\title{
Processo de ocupação e sistemas de produção em pequenas propriedades rurais: o caso do parque estadual do Turvo
}

\author{
Romualdo Kohler ${ }^{1}$ \\ Neimar Damian Peroni ${ }^{2}$ \\ Adriano Roque de Gasperin ${ }^{3}$ \\ Yosani Morales Martinez ${ }^{4}$ \\ Camila Saturno ${ }^{5}$
}

\begin{abstract}
Resumo: Esse artigo objetiva identificar as estratégias de reprodução econômica, realizar a avaliação econômica dos sistemas de produção e sopesar as potencialidades nas propriedades limítrofes ao Parque Estadual do Turvo, Brasil. Também traz uma descrição do processo de ocupação, das restrições na produção, no passado e no presente. A metodologia segue a abordagem da Teoria dos Sistemas Agrários, que valoriza os atores da história dos processos produtivos, para além do estudo da capacidade de reprodução social na propriedade rural. Como resultado da análise econômica, as unidades estudadas foram consideradas economicamente viáveis, com retorno maior que o custo de oportunidade referenciado.
\end{abstract}

Palavras-Chave: Parque Estadual do Turvo; Teoria dos Sistemas Agrários; Ocupação territorial.

\section{OCCUPATION PROCESS AND PRODUCTION SYSTEMS IN SMALL RURAL PROPERTIES: THE CASE OF TURVO STATE PARK}

AbSTRaCT: This article aims to identify the economic reproduction strategies, to accomplish the economic evaluation of the production systems and to assess the potentialities in the properties adjacent to Turvo State Park, Brazil. It also gives a description of the occupation process, the constraints on production, past and present. The methodology follows the approach of the Theory of Agrarian Systems, which values the actors of the history of the productive processes, besides the study of the capacity of social reproduction in the rural property. As a result of the economic analysis, the units studied were considered economically viable, with a return greater than the referenced opportunity cost.

KEYwORDS: Turvo State Park; Theory of Agrarian Systems; Territorial occupation.

\footnotetext{
${ }^{1}$ Professor Permanente no Programa de Pós-Graduação Stricto Sensu em Desenvolvimento Regional - Mestrado e Doutorado - UNIJUÍ.E-mail: romualdo@unijui.edu.br.

${ }^{2}$ Doutor em Extensão Rural pela Universidade Federal de Santa Maria (UFSM), Engenheiro agrônomo - EMATER/RS. E-mail: neimar@emater.tche.br

${ }^{3}$ Mestre em Extensão Rural - Universidade Federal de Santa Maria (UFSM), Engenheiro agrônomo - EMATER/RS. E-mail: adrianogasperin@gmail.com

${ }^{4}$ Mestre em Extensão Rural - Universidade Federal de Santa Maria (UFSM), Ingeniera en Desarrollo Comunitario - Instituto Tecnológico de Comitán - México. E-mail: yosa-12@hotmail.com

${ }^{5}$ Especialista em Educação Ambiental (UFSM) e Licenciamento Ambiental (UNIJUÍ), Bióloga - UNIJUÍ/RS. E-mail: kamilasatur@yahoo.com.br
} 


\section{INTRODUÇÃO}

O presente artigo tem objetivo de identificar as estratégias de reprodução econômica e os sistemas de produção dos agricultores que possuem propriedades limítrofes ao Parque Estadual do Turvo (PET), localizado no município de Derrubadas, no Rio Grande do Sul. Em um primeiro momento se busca descrever o processo de ocupação das áreas, a partir dos relatos de moradores mais antigos, e identificar as restrições encontradas na produção ao lado de área de conservação da flora e fauna nativas, no passado e no presente. Na segunda parte do trabalho, se almeja proceder à identificação dos tipos de exploração, fazer a avaliação econômica dos sistemas de produção encontrados e avaliar as potencialidades e limites das estratégias de reprodução econômica empregadas.

Os procedimentos metodológicos empregados seguem a Teoria dos Sistemas Agrários e, assim, foram trabalhados, concomitantemente, o diagnóstico dos sistemas de produção agrícolas predominantes no entorno e a escala de análise da Unidade de Produção Agrícola (UPA).

Neste contexto, seguem-se considerações teórico-metodológicas sobre a Teoria dos Sistemas Agrários e a análise e discussão dos resultados da investigação.

\section{CONSIDERaÇões teórico-Metodológicas Sobre a TeOria dos Sistemas} Agrários

Existem vários métodos para análise de sistemas agrários, cada qual com suas especificidades, epigrafando aspectos pontuais dos processos técnicos e econômicos. Todavia, como se procura avaliar a complexidade no entorno do Parque Estadual do Turvo - PET, optou-se por resgatar uma metodologia que valoriza os atores da história dos sistemas agrários, conhecida na literatura como Teoria dos Sistemas Agrários.

Segundo SILVA NETO (1997), a Teoria dos Sistemas Agrários tem origem na Cátedra de Agricultura Comparada e Desenvolvimento do Instituto Nacional Agronômico de Paris-Grignon, na França e foi desenvolvida para servir de instrumento de análise da evolução histórica e da diferenciação geográfica da agricultura.

De acordo com o mesmo autor, em outra publicação:

"Os sistemas de produção correspondem à forma como os agricultores organizam as suas atividades no interior das unidades de produção. A diversidade de situações ecológicas e sociais e a experiência específica acumulada pelos agricultores fazem com que jamais duas unidades de produção tenham sistemas de produção perfeitamente iguais." (SILVA 
NETO, p.27, 2015).

Neste contexto, a Teoria dos Sistemas Agrários amplifica o campo de observação dos sistemas agrários e das unidades de produção, buscando explicar e não somente descrever os fenômenos, a partir da manutenção da perspectiva histórica em todas as etapas do processo e da realização de avaliação econômica em diferentes sistemas de produção, preservando a especificidade de cada unidade produtiva.

Assim, na presente investigação se buscou coletar informações sobre o funcionamento do sistema, trajetória histórica da propriedade e objetivos dos produtores e suas famílias através de instrumento denominado "enquete", que é uma forma de pesquisa feita de maneira direta aos moradores locais, um método qualitativo de investigação, a partir de entrevistas abertas, gravadas, com moradores mais antigos da localidade. O propósito destes procedimentos segue na direção de compreender, explorar e descrever os acontecimentos e os contextos envolvidos na ocupação e desenvolvimento das atividades agropecuárias no entorno do PET.

Por outro lado, a análise econômica busca a determinação dos resultados econômicos da Unidade de Produção Agrícola - UPA. Para os objetivos do estudo foram selecionadas em número de três, por suas estruturas produtivas distintas entre si e representativas no entorno do PET. Seguiu-se, à luz da Teoria dos Sistemas Agrários, o modelo da determinação do Valor Agregado (VA), que se caracteriza como uma medida de valor econômico, que avalia a atividade produtiva da unidade de produção durante um ano de trabalho.

As variáveis de análise que fazem parte da matriz do cálculo do VA, segundo a metodologia adotada, são:

- Superfície Agrícola Útil (SAU): refere-se ao espaço geográfico destinado à produção agrícola na propriedade rural, identificado em hectares (ha).

- Unidade de Trabalho Homem (UTH): representa o número de trabalhadores envolvidos no processo produtivo.

- Produto Bruto (PB): representa o valor bruto dos produtos e serviços finais gerados exclusivamente pela unidade de produção durante um ano e, no seu cálculo são considerados os preços e as quantidades vendidas.

- Consumo Intermediário (CI): refere-se aos bens e serviços comprados e consumidos no decorrer do ciclo produção pelo estabelecimento agrícola. São denominados de intermediários porque são transformados no decorrer do processo produtivo.

- Depreciação (D): corresponde à fração dos meios de produção adquiridos pela unidade de outros agentes (máquinas, instalações, equipamentos) que não são integralmente consumidos no decorrer de um ciclo produtivo, ou melhor, cor- 
responde ao desgaste da capacidade produtiva instalada.

- Valor Agregado (VA): mede o valor adicionado, ou seja, o valor gerado pela unidade de produção. Sua determinação permite comparar as atividades produtivas de unidades diferenciadas, sob o ponto de vista do domínio dos meios de produção. O VA pode ser medido de duas formas: Bruto ou Líquido.

- Valor Agregado Bruto (VAB): corresponde ao resultado do Produto Bruto descontado o Consumo Intermediário $(\mathrm{VAB}=\mathrm{PB}-\mathrm{CI})$.

- Valor Agregado Líquido (VAL): deduz-se do Valor Agregado Bruto a Depreciação (VAL $=\mathrm{PB}-\mathrm{CI}-\mathrm{D})$.

- Renda Agrícola (RA): é o resultado da unidade de produção no decorrer de um ciclo produtivo, subtraída, a parte do Valor Agregado Líquido gerado, que é repartido com os outros agentes que participaram do processo produtivo, ou seja, os custos dos outros fatores de produção: mão de obra contratada de terceiros = salários; terra = arrendamento; capital financeiro $=$ juros, e, ainda, a parcela do Governo = tributos. De outra forma, a RA corresponde à remuneração real da mão de obra familiar, a parte da riqueza gerada pela unidade de produção que corresponde ao agricultor, após a distribuição do Valor Agregado.

- $\quad$ Nível de Reprodução Simples (NRS): é a renda mínima necessária para reproduzir os meios de produção da unidade e remunerar o trabalho familiar ao longo do tempo. Em síntese, é o lucro final da UPA, descontados todos os custos envolvidos na produção, dividido por UTH. Representa uma medida do custo de oportunidade do trabalho, no caso, do Salário Mínimo (SM), ou seja, quantos SM's restaram ao produtor no final de um ano de processo produtivo.

A partir deste contexto teórico-metodológico, se avança, a seguir, para os resultados e discussões da investigação.

\section{O Parque Estadual do Turvo e propriedades limítrofes}

A área de conservação foi criada a partir do Decreto Estadual no 2.312, de 11 de março de 1947, como Reserva Florestal Estadual, com uma área de 17.637,50 hectares. Mais tarde, o Governador do Estado do Rio Grande do Sul, conforme Lei $\mathrm{n}^{\circ} 2.440$ de 2 de outubro de 1954, transformou a reserva em Parque Estadual do Turvo. A unidade faz limite pelo Rio Uruguai ao norte com a Argentina e com o estado de Santa Catarina. Ao sul, leste e oeste, faz divisas com propriedades privadas, objeto desse estudo.

A região que compreende Derrubadas e o Parque Estadual do Turvo (PET) apresenta quatro bacias hidrográficas distintas: Rio Parizinho, Arroio Mairosa, Arroio Calixto e Rio Turvo, todos afluentes do Rio Uruguai. Como caracterís- 
tica geral, as bacias apresentam grande declividade, formando vales estreitos e profundos. A região que compreende Derrubadas e o Parque Estadual do Turvo (PET) apresenta quatro bacias hidrográficas distintas: Rio Parizinho, Arroio Mairosa, Arroio Calixto e Rio Turvo, todos afluentes do Rio Uruguai. Como característica geral, as bacias apresentam grande declividade, formando vales estreitos e profundos. A ocorrência de solos pouco espessos, de baixa permeabilidade e predominância de áreas desflorestadas (a exceção ao PET), propiciam um escoamento superficial elevado e muito rápido, originando um regime fluvial ligado ao regime pluvial (ANA, 2015).

Figura 1 - Mapa de localização de Derrubadas e o Parque do Turvo.

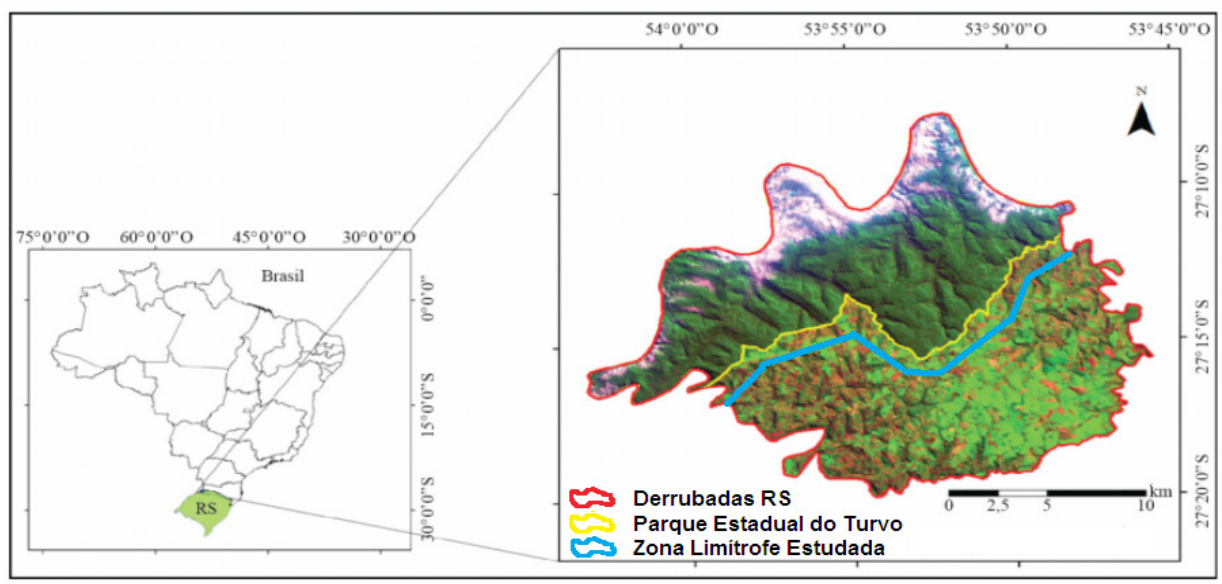

Fonte: Adaptado de ROSA, P.A. et al. (2013).

A vegetação do PET é um dos últimos redutos representativos da mata fluvial do Alto Uruguai. (BRACK et al., 1985), Os autores relatam que foram identificadas 727 espécies vegetais na área do parque, abrigando uma grande diversidade de espécies aliadas à ocorrência de espécies endêmicas. Possui ainda uma das únicas áreas de florestas contínuas do Alto Uruguai. Esta área representa hoje um dos últimos refúgios, no Estado, para espécies de grandes mamíferos como onças-pintadas e antas. Wallauer e Albuquerque, (1986) citam que há 30 espécies de mamíferos no Parque, muitas ameaçadas de extinção.

\section{O PROCESSO DE OCUPAÇÃO POR COLONOS}

A ocupação dos lotes limítrofes ao parque por imigrantes se deu na década de 1940. Um participante da pesquisa relatou que os avós vieram da Itália para 
colônias da região de farroupilha. Em 1944 o pai, então com 21 anos e três filhos, adquiriu um lote unido ao parque, onde reside hoje. A área adquirida de 27,6 hectares foi alcançada com dificuldades:

"o pai veio de caminhão até a localidade do Cedro Marcado, onde se hospedou por três dias até conseguir transporte pra propriedade. Foi de carroça por $6 \mathrm{~km}$ até Derrubadas e depois com o cavalo mais $3 \mathrm{~km}$, carregando a mudança atada no lombo, por um pique na mata utilizado, já naquela época por contrabandistas de pneus da Argentina. Pra entrar na área ele mesmo ia abrindo" (PARTICIPANTE DA PESQUISA, 2015).

O imóvel foi adquirido do governo e os motivos que levaram o genitor a escolher o local foram ligados à possibilidade de no futuro adquirir mais áreas, à medida que os filhos crescessem, adentrando ao parque, fato não ocorrido, pois a área de proteção consolidou-se e manteve com ela os seus limites geográficos.

Outra participante da pesquisa, de 80 anos, residente há 53 anos na propriedade de 11 hectares, contígua ao parque - veio morar casada e já com três filhos. Antes residiu nas cercanias, na localidade Olhos D’água. Era menina quando os pais compraram a propriedade em 1947 e recorda que ao chegarem, queimaram um pedaço de mato para poder construir a casa. A casa foi construída serrando algumas árvores, lascando e falquejando a madeira para fazer as tábuas. Para o telhado faziam o mesmo processo em pequenas tabuinhas, que depois de secas perfuravam e torneavam, colocando um pequeno pino de madeira para fixar na estrutura de madeira da cobertura.

Por sua vez, outro agricultor aposentado narra que os pais vieram do município de Três Passos para instalar uma serraria em 1945. A primeira casa foi construída de pranchas lascadas a machado da Corticeira da Serra (Erythrina falcata), que embora durasse 3 a 4 anos apenas, era madeira macia fácil de trabalhar. Para fechar as frestas, utilizavam a casca do Louro (Cordia trichotoma) pela facilidade de soltar do tronco.

Um Guarda-Parque, filho de agricultor, residente no município há 50 anos, conta que os pais migraram da região central do estado em busca de terra boa e barata. Compraram o título da propriedade e posteriormente "o pai gastou bastante para regularizar”. Segundo o mesmo interlocutor, os primeiros moradores da localidade, anteriores à aquisição de sua família, chegavam ao local demarcavam uma área e se apossavam. Posteriormente vieram os agrimensores do governo para demarcar. A figura 2 mostra a demarcação oficial dos lotes, totalizando 290 unidades. 
Figura 2 - Lotes rurais de colonização de Derrubadas RS.

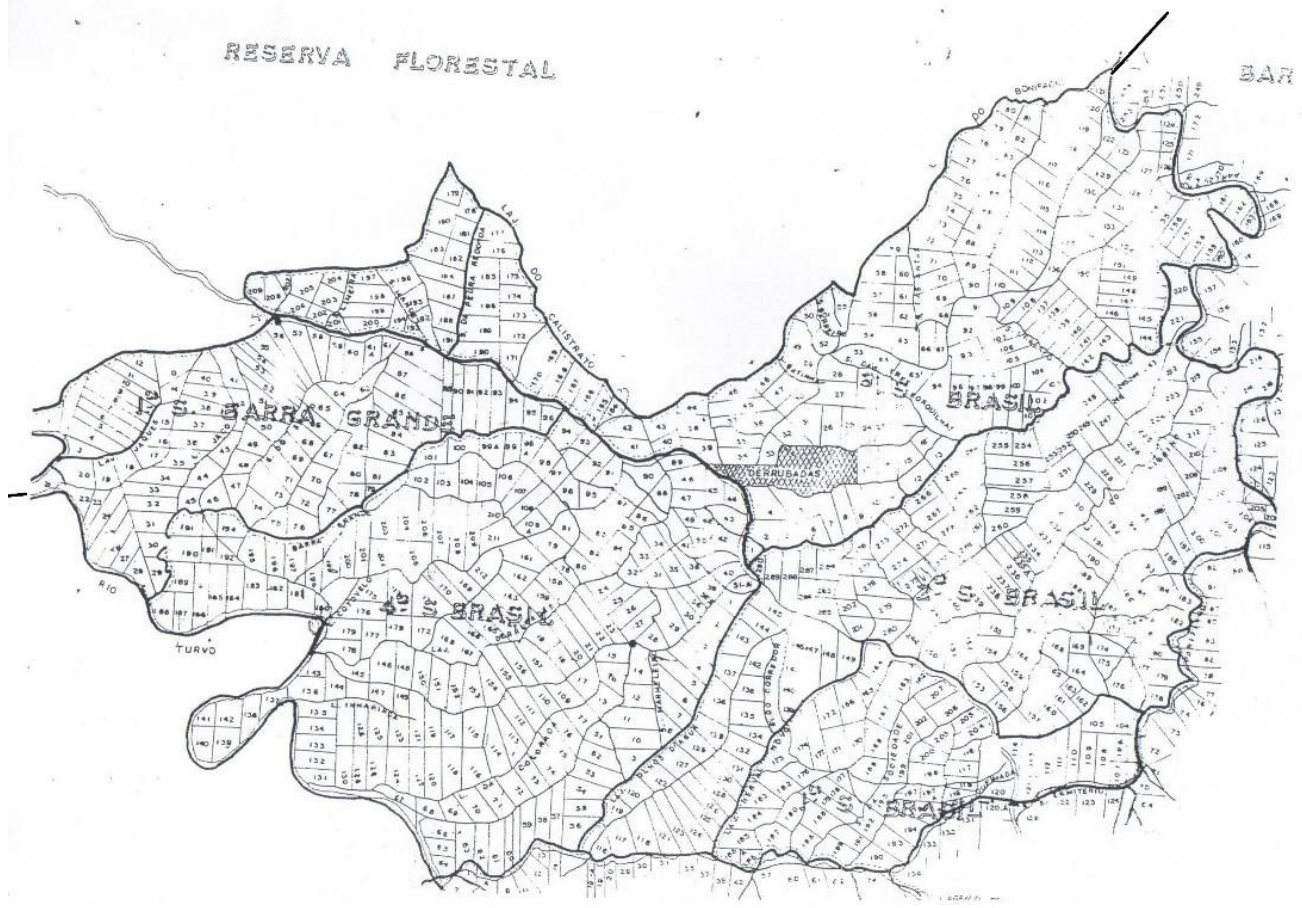

Fonte: Prefeitura Municipal de Derrubadas (2015).

São reconhecidos por terem sobrenomes portugueses em comparação com nomes alemães, italianos e poloneses dos colonizadores. O cemitério tem cerca de 130 anos e é do tempo dos "sete palmos e meio", relata a agricultora, e que seu filho ajudou a abrir as covas em que era necessário cavar até atingir essa medida. Esses moradores ocupavam áreas ao longo da parte oeste do parque, e, posteriormente, foram reassentados em uma fração que pertencia à área de proteção que foi destinada a regularização fundiária dessas famílias. A reserva diminuiu um pouco de tamanho, mas impôs limites para a ocupação.

A remoção dos posseiros é explicada pelo Guarda Parque, que afirma existirem vários resquícios de taperas e pequenas áreas de cultivo no interior do PET. Alguns ocupantes extraiam madeira nos anos 30 e 40 e, a área intangível (floresta sem sofrer ação humana) totaliza cerca de $70 \%$ da área, aquela com topografia mais acidentada e de difícil acesso. Um participante da pesquisa traz explicações para a ocupação do setor oeste, próxima ao rio Turvo. Segundo o entrevistado, essa ocupação aconteceu na época da revolução de 1923, que envolveu em todo o Rio 
Grande do Sul a disputa entre "chimangos", partidários do governo de Borges de Medeiros e "maragatos", revolucionários liderados por Assis Brasil. Muitos integrantes do segundo grupo, em derrocada, subiam em canoas pelo Rio Uruguai, para se ocultar, pois eram perseguidos por legalistas.

"Uns moravam no salto do Yucumã. Eram nove irmãos. O seu João Sarampião, guarda antigo do parque, era filho de um deles. Tinham o acampamento na Barra do Mairosa. Tem os cepos das casas deles. Vinham fazia as casas, derrubavam uma quarta de mato e plantavam milho. Criavam porco solto e viviam de caça e pesca. Pescavam na mangueira do salto. Daí veio os inimigos de atrás e mataram muita gente. Eles escaparam porque passaram pra Argentina pela Pedra Bugra. Viveram anos na Argentina, depois voltaram. O finado Rosalino, que era o primeiro guarda do parque também passou por isso. Ele contava.” (PARTICPANTE DA PESQUISA, 2015)

No município de Derrubadas, nas proximidades do Parque, existe uma localidade denominada "Desimigrados", que tem origem no estabelecimento deles ali após a expulsão da Argentina. Coaduna com a opinião de outro entrevistado, em que a sensação na infância, passada por relatos paternos, era que os habitantes antigos eram "fugitivos, sem paragem, que ora estavam no Brasil, ora na Argentina e que os mais perigosos eram os que moravam no parque". Era "um recanto do estado buscado para se esconder dos seus feitos" (PARTICIPANTE DA PESQUISA, 2015).

Os ocupantes antigos viviam de pequenas roças de feijão, batata e mandioca e caçavam: "naquele tempo, se tinha comia, se não tinha, ficava com a barriga roncando" lembra uma entrevistada. Aos poucos esses moradores foram saindo do local, vendendo suas terras pouco valorizadas. O avô de sua nora, há cerca de 50 anos atrás trocou por necessidade, um hectare de terra por uma "costela e um quarto de porco". A precariedade também foi enfrentada por sua família "a gente tinha mal as penas para viver, às vezes levava um produto para o comércio, se não se agradassem trazia de volta".

\section{O PARQUE E A RELAÇÃo COM A SUBSISTÊNCIA DAS FAMÍLIAS}

Em 1947 o então interventor do estado Cylon Rosa criou a Reserva Florestal do Turvo (transformado em Parque em 1954) e determinou, no decreto, a sua circunscrição. Uma indagação foi recorrente durante a execução do trabalho de campo e a realização das entrevistas: o que levou à criação do PET naquela época e na localidade? Os partipantes da pesquisa pouco sabiam sobre o tema, contudo a narrativa de um entrevistado pode dar indicações do acontecido: a autoridade que o criou, conhecia e frequentava periodicamente a região: 
“O doutor Cylon Rosa eu conheci. Ele vinha de Porto Alegre pra cá. Vinha numa frota de automóvel a fim de caçar e pescar, existia um armazém de comércio, na época, na esquina aqui em cima, do Helmuth Koester Eles acampavam dentro do armazém. Ele trazia aquela frota de 3, 4 ou 5 carros. Era conhecido por ai. Iam até Porto Garcia, pagavam alguém pra levar de lanchão pra Argentina. Tinham uns lugares muito bom de caça e pesca lá. As estradas e os carros não eram como são hoje. Eram uns 29 e 36 . Uma vez por causa da chuvarada ficaram dias. O comerciante, que era meu tio, comprava de tudo que os colonos produziam. O tio tinha um tonel de mel e bastante amendoim. Quando a comitiva foi embora ele veio se queixar: -Eu não cobro nada, mas me deram prejuízo, comeram quase todo meu amendoim e o mel, que estava açucarado" (PARTICIPANTE DA PESQUISA, 2015).

A área inicial do PET era maior, mas para regularizar a situação de moradores, foi cedida a área já referida para reassentamento. Fruto disso, hoje o parque é o único do Estado que não tem problemas fundiários.

Um lindeiro conta que a divisa entre parque e propriedade de seu pai era apenas uma picada, que delimitava o espaço público do privado. Disseram a ele na aquisição: "até aqui é teu, ali é do estado, até aqui tu pode ir, ali não". Inicialmente eram cultivados apenas produtos para a subsistência familiar, como mandioca, batatas e milho - este vendido para adquirir suínos de vizinhos. A caça era uma atividade frequente, às vezes diária, que supria as necessidades familiares e protegia os cultivos:

"De todo lote se cultivava em 3 ou 4 ha, o resto era mato, de noite alguém tinha que ficar cuidando, porque vinham 30 a 40 porcos do mato pra comer o que se plantava, se não comiam tudo, estragavam. Era o que nossa família, pai, mãe e nós 20 filhos iriam comer durante todo ano. Tinha que cuidar. E a gente não precisava entrar no parque pra caçar, se caçava ali mesmo" (PARTICIPANTE DA PESQUISA, 2015).

Os colonos chegavam "derrubavam mato queimavam, plantavam, colhiam, deixavam criar capoeira, roçavam, queimavam, plantavam e assim ia, tudo a base de fogo" lembra um filho dos primeiros colonos.Outra agricultora aposentada, residente há 50 anos no local, com 72 anos, conta que casou e veio residir na área ao lado da reserva com os sogros, dos quais cuidou até o final da vida. Relata as dificuldades de cultivo das lavouras de subsistência feito a "enxada e arado de bois, tudo a muque". Posteriormente utilizavam uma trilhadeira estacionária, já para as lavouras comerciais criavam também suínos e bovinos de leite, onde financiaram 
o estábulo a troco de milho, no Feaper6, para pagar em vários anos.

Em relação ao convívio com o parque vizinho, relata que desde que foram residir no local em meados da década de 1960, existiam guardas para fiscalização e que se colocavam a disposição caso acontecesse algum transtorno em relação animais, especialmente onças.

Corriqueiramente perdiam cães: "criamos, acho, mais de trinta cachorros, quando se via, sumia, a onça matava". Na avaliação atual, não sabe como não sentiam medo, pois trilhavam até anoitecer em regiões próximas ao mato. Contudo no final da década de 1970, pelas frequentes investidas do felino ao redor da residência, atacando e devorando cães em noites seguidas, foi solicitada ajuda aos guardas. Utilizaram uma gaiola e um cão como isca e capturaram um exemplar que pesou $56 \mathrm{~kg}$. Foi a única vez que viu a espécie, pois só percebia rastros Depois de medido e apresilhado a uma coleira com rádio transmissor, o animal foi solto dentro do parque em outra região.

Outros animais invadiam o espaço das propriedades, como a cotia, porco do mato, anta e quatis. Cada um com uma algumas características e predileções:

"A cotia comia segurando com as patas da frente; o porco do mato depois que descobria uma lavoura não salvava nada; a anta saia depois da chuva e comia a parte de cima de muita planta de soja; os quatis atacavam as laranjeiras, em bando de até 50 bichos, pequenos e grandes. Em pouco tempo comiam tudo. Era até lindo de ver" (PARTICIPANTE DA PESQUISA 2015).

A entrevistada lembra que sempre defendeu a proibição da caça, mas acredita que ainda hoje existem alguns caçadores que burlam a legislação: "vem de fora, fazem espera, buscam principalmente antas, pois diz que tem carne boa".

São apenas pontuais as informações de danos causados por animais silvestres nas áreas de cultivo, confirmando o relato anterior: "no ano passado perdi a produção de 30 pés de bergamota, os quatis atacavam em bando, trepavam nas árvores e não deixaram uma", relata um fruticultor. Ele também aponta que um vizinho, para não perder o milho, instalou uma cerca elétrica com 3 fios para impedir a presença de animais na lavoura.

Outra fonte, em região oposta, relata casos de porcos do mato atacando a lavoura de mandioca do vizinho recentemente: eram mais de 50 porcos, que durante o dia acabaram liquidando o cultivo. Conta ainda que não é comum aparecer animal fora do PET ultimamente, contudo, há poucos anos apareceu um filhote

\footnotetext{
${ }^{6}$ Fundo Estadual de Apoio ao Desenvolvimento dos Pequenos Estabelecimentos Rurais, criado pela Lei Estadual do Rio Grande do Sul n. ${ }^{\circ} 8.511$, de 6 de janeiro de 1988.
} 
que ela imaginava ser um porco: "fiquei com pena do bichinho, tratei, depois vi que era um tateto ${ }^{7}$. Quando atingiu uns vinte quilos chamei o homem do parque e entreguei. Diz que levam pra um zoológico". Indagada porque não permaneceu com ele, argumentou sobre a proibição, demonstrando a mesma compreensão dos outros entrevistados sobre a preponderância da autoridade da lei ambiental e da possibilidade de punição.

\section{CONTINGÊNCIAS ATUAIS DE VIDA E PRODUÇÃo}

Em torno do parque as partes mais acidentadas permanecem com moradores. As áreas possíveis de plantio de soja e bem mais valorizadas, valendo o equivalente a 500 a 700 sacas por hectare, foram adquiridas por produtores de grãos que residem noutras localidades. A juventude do local é escassa: “daqui até o Rio Turvo tem umas cinco ou seis propriedades", relata uma moradora: "o único jovem de todas, é meu neto na próxima propriedade" (PARTICIPANTE DA PESQUISA, 2015).

Os outros quatro netos que residiam com a agricultora aposentada mudaram-se: uma pelo casamento outros três para trabalhar na região da produção de calçados em Ivoti. As atividades econômicas na propriedade são reduzidas, pois moram apenas ela e o filho de 53 anos que apresenta problemas de saúde proporcionados pelo alcoolismo: "cultivamos umas roças e criamos umas vaquinhas"; "o resto é completado pela aposentadoria, graças a Deus".

A agricultora da propriedade em que foi capturada a onça relata que os dois filhos estudaram e iniciaram um empreendimento no setor de turismo, com balneário e hospedagem. Os pais permaneceram nas atividades agropecuárias e posteriormente abandonaram primeiro a atividade leiteira e posteriormente as demais. Atualmente residem no núcleo urbano, apenas um filho na propriedade e o outro trabalha na cidade.Da família com vinte filhos, só o décimo terceiro no nascimento, permanece no local. Ao pedido do pai retornou do seminário aos 17 anos para continuar a produção. Os demais membros masculinos saíram por suas conveniências ou por incompatibilidades com genitor. As irmãs saíram com o casamento. A terra dos demais herdeiros foi adquirida no processo de herança, após a morte dos pais. A mão de obra é um limitador das atividades de hortigranjeiros e fruticultura, pois agora, somente ele e a esposa residem e trabalham no imóvel. Os dois filhos mais velhos trabalham na cidade e a mais nova cursa Universidade pública em outro município.

Quanto ao esvaziamento do meio rural acreditam os entrevistados que hoje muitos estudam e vão trabalhar na cidade. "Se tu puder fazer algo, faz, se não deixa", relata uma agricultora, pois não existem mais "peões" como existiam

${ }^{7}$ Expressão regional para Tayassu tajacu. 
antigamente. Os caboclos ${ }^{8}$ e os filhos saíram pra trabalhar na cidade. Outro processo de esvaziamento da vizinhança aconteceu na década de 1970 com os projetos de colonização do Mato Grosso, principalmente Canarana ${ }^{9}$ arrigementado na região pela Igreja Luterana. O argumento para o reassentamento era a ampliação de área das propriedades, em ate dez a vinte vezes do que vendiam. A argumentação dos idealizadores do projeto era que "iria chegar um tempo em que só vai ter o bem grande e o bem pequeninho e os colonos não iriam se manter com pouca terra, tinham que pegar mais". Na ida os mais capitalizados prosperaram e outros, perderam tudo, conforme narra a participante.

Dos 68 proprietários limítrofes ao parque do loteamento, conforme mapa na figura 2, foram registrados apenas 46 produtores, com uma redução de cerca de $30 \%$. A redução é possivelmente maior, pois muitos dos lotes iniciais foram subdivididos em processos hereditários, comportando na atualidade mais de um proprietário. A concentração ocorre mais na região oeste, onde um só agricultor faz fronteira com a reserva por cerca de $5 \mathrm{~km}$, resultado da aquisição de áreas.

\section{Análise econômica das Unidades de Produção Familiares (UPAS)}

A segunda parte do trabalho apresenta os principais tipos de exploração identificados, nas propriedades do entorno do PET. A avaliação econômica dos sistemas de produção e as potencialidades, limites das estratégias de reprodução econômicas empregadas são analisadas em três propriedades representativas do entorno do PET.

\section{UPA-1: Produção de grãos (MILHO E SOJA) E bovinocultura de CORTE}

\section{E LEITE}

Propriedade com área total de 38,8 ha onde são produzidos 14 ha de soja, 5 ha de milho para silagem, 5 ha de milho para grãos ( 2 ha para CI e 3 ha são para venda) e 7,8 ha para pastagem e 7 ha de mato, perfazendo uma Superfície Agrícola Útil (SAU) de 31,8 ha. A unidade produtiva familiar possui 12 cabeças de gado destinadas ao corte e 17 vacas para produção de leite. A propriedade conta com 3 Unidades de Trabalho Homem (UTH). A UPA tem na bovinocultura de leite sua atividade principal.

De acordo com a Tabela 1, cada SAU proporciona $\mathrm{R} \$ 5.726,23$ de produto bruto total. Já o VAB/SAU corresponde a R \$3.308,24, o que é notadamente inferior ao

\footnotetext{
${ }^{8}$ Expressão regional para definir os moradores mais antigos do local.

${ }^{9}$ Projeto de colonização desenvolvido no município de Barra do Garças (MT) iniciado em 1972 desenvolvido pelo Governo Militar e executado pela Cooperativa de Colonização 31 de Março LTDA (COOPERCOL) com pequenos agricultores oriundos de Tenente Portela (RS).
} 
$\mathrm{PB} / \mathrm{SAU}$, devido ao consumo intermediário, o qual corresponde a $42,23 \%$ de todo o PB gerado. A renda agrícola por UTH corresponde a R $\$ 30.251,83$, correspondendo a $\mathrm{R} \$ 2.520,99$ mensais. Esta é a remuneração real da mão de obra familiar, sendo 2,64 vezes superior ao NRS (Salário Mínimo/2018=R $\$$ 954,00), mostrando que a UPA é economicamente viável.

O NRS total da UPA é de R \$34.320,00, sendo atingido com uma SAU de 13,02 ha, considerando a atividade de bovinocultura de leite como a que gera maior riqueza, contemplando $58,53 \%$ da RA total.

Tabela 1 - Indicadores econômicos da UPA-1 com sistema de produção de grãos (milho e soja) e bovinocultura de corte e leite.

\begin{tabular}{c|c}
\hline INDICADORES GERAIS & VALORES \\
\hline $\mathrm{PB} / \mathrm{SAU}$ & $\mathrm{R} \$ 5.726,23$ \\
$\mathrm{VAB} / \mathrm{SAU}$ & $\mathrm{R} \$ 3.308,24$ \\
$\mathrm{VAL} / \mathrm{SAU}$ & $\mathrm{R} \$ 3.033,08$ \\
$\mathrm{RA} / \mathrm{SAU}$ & $\mathrm{R} \$ 2.853,95$ \\
$\mathrm{CI} / \mathrm{PB}$ & $42,23 \%$ \\
$\mathrm{DEP} / \mathrm{PB}$ & $4,81 \%$ \\
$\mathrm{RA} / \mathrm{PB}$ & $49,84 \%$ \\
$\mathrm{RA} / \mathrm{UTH}$ & $\mathrm{R} \$ 30.251,83$ \\
$\mathrm{RA} / \mathrm{UTH} / \mathrm{MENS}$ & $\mathrm{R} \$ 2.520,99$ \\
$\mathrm{RA} / \mathrm{NRS}$ & 2,64 \\
\hline
\end{tabular}

Fonte: Elaborado pelos autores, com base nos dados da pesquisa.

Figura 3 - Valor Agregado Líquido e Nível de Reprodução Simples da UPA-1.

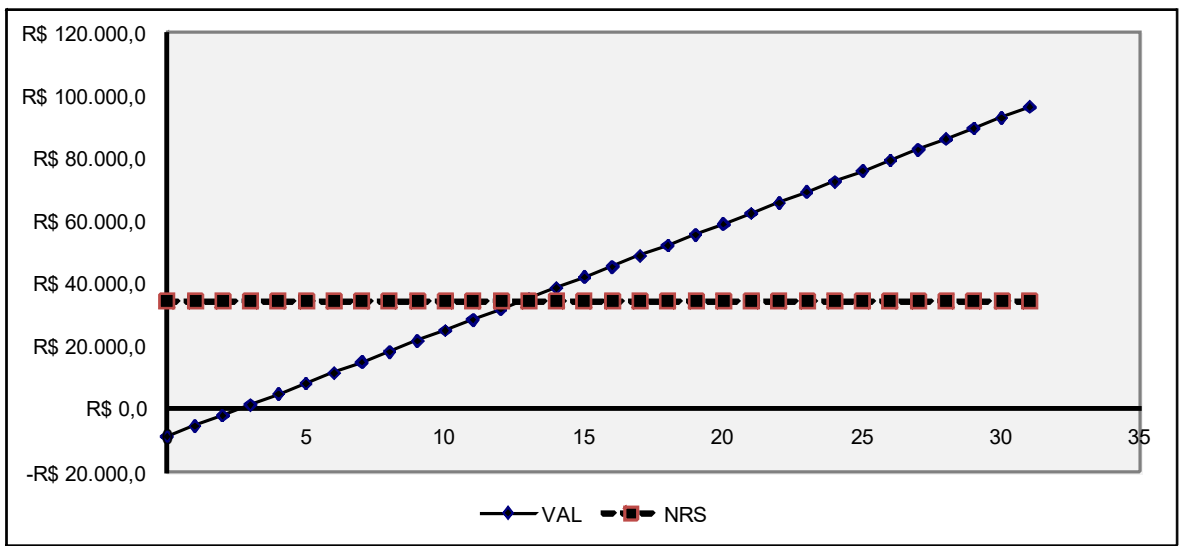

Fonte: Elaborado pelos autores, com base nos dados da pesquisa. 
Dentre as atividades desenvolvidas na propriedade a bovinocultura de leite é responsável pela maior renda agrícola por unidades de área e também por unidade de trabalho homem (Figura 4). O milho tem o menor retorno em renda agrícola por unidade de área e por unidade de trabalho homem. No entanto, não se recomenda substituir a cultura por outra mais rentável como a soja, visto que o milho tem importante função agronômica na conservação do solo como rotação de cultura e também porque o produto sofre oscilações frequentes de preços, o que pode gerar maior retorno futuro. Um aumento de $\mathrm{R} \$ 0,10$ por quilo do produto traria uma $\mathrm{RA} /$ ha de R $\$ 2102,19$, superior a soja e a bovinocultura de corte, e uma RA/UTH também de R \$2102,19 (UTH=ha=3). Visando a diversificação e a redução de risco da propriedade não é aconselhável a substituição da bovinocultura de corte por outra atividade, uma vez que sua RA/PB é de $68,69 \%$, ou seja um baixo CI e DEP.

Figura 4 - Desempenho da RA/ha e da RA/UTH na UPA-1.

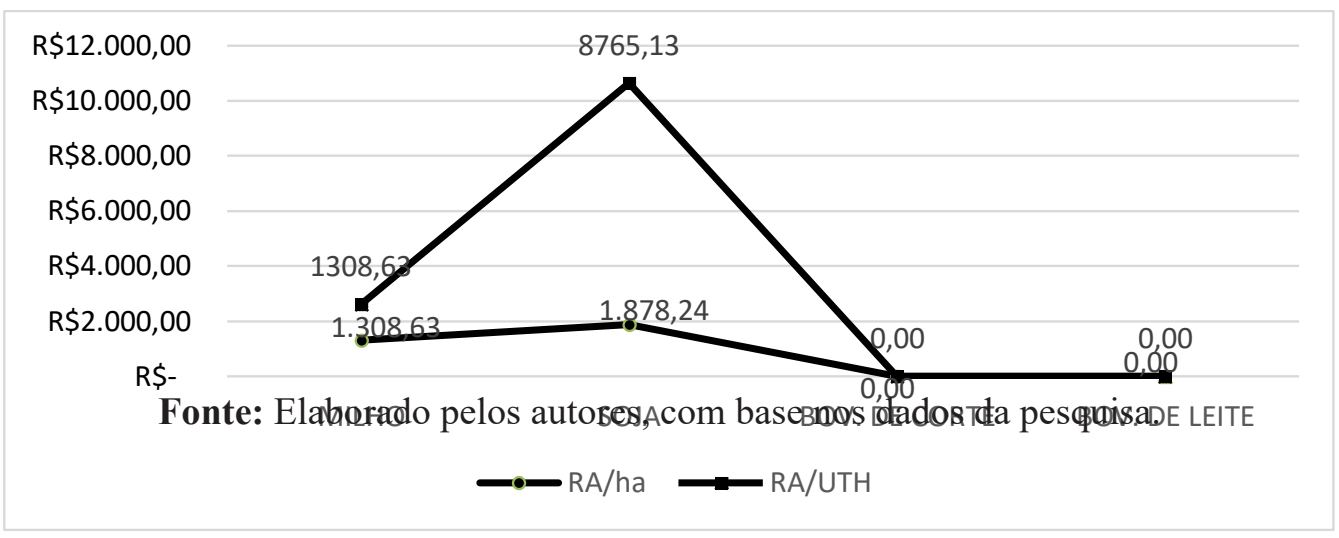

Fonte: Elaborado pelos autores, com base nos dados da pesquisa.

\section{UPA-2: ProduÇÃo de Grãos (MILHO E SOJA) E boVINOCULTURA de CORTE}

\section{E LEITE}

A UPA-2 cultiva 8 ha milho, 4 ha destinados para silagem e 4 ha para grão (vendeu $160 \mathrm{sc}$ ), 8 ha de soja, 2 ha de pastagem e 2 ha de mato totalizando 20 ha e uma superfície agrícola útil de 16 ha. A unidade produtiva familiar possui 10 cabeças de gado destinadas para corte e 17 vacas para produção de leite. A propriedade conta com 2 Unidades de Trabalho Homem (UTH). A UPA tem na bovinocultura de corte sua atividade principal, sendo que 52,27\% da RA é provem dela.

Assim, a UPA gerou um PB de R\$ 104.976,60, sendo que a bovinocultura de corte corresponde a $47 \%$ desse $\mathrm{PB}$, seguido por bovinocultura de corte com $27 \%$, 
soja com $22 \%$ e milho $4 \%$. A propriedade gerou um PB/SAU de R\$ 6.333,04, descontando um CI/SAU de 50,02\% tem-se um VAB/SAU de R \$ 3.164,98 (Tabela 2). O peso da depreciação sobre o PB corresponde a 7,83\%. A taxa de rentabilidade sobre o PB é de 37,87\%, o que demonstra que de cada $\mathrm{R} \$ 100,00$ de PB gerados $\mathrm{R} \$ 37,87$ é renda agrícola líquida. Esta RA proporciona um valor de R\$19.186,52 por UTH durante o ano, e R\$ $1.598,88$ por mês.

O NRS total da UPA é de R\$22.880,00, sendo que a propriedade consegue atingir essa RA com uma SAU de 9,73ha (Figura 3). A atividade de bovinocultura de corte é a que maior riqueza, contemplando 52,27\%da RA total. A RA da UPA corresponde a 1,68 vezes o NRS.

Tabela 2 - Indicadores econômicos da UPA-2, com sistema de produção de grãos (milho e soja) e bovinocultura de corte e leite.

\begin{tabular}{c|c}
\hline INDICADORES GERAIS & VALORES \\
\hline $\mathrm{PB} / \mathrm{SAU}$ & $\mathrm{R} \$ 6.333,04$ \\
$\mathrm{VAB} / \mathrm{SAU}$ & $\mathrm{R} \$ 3.164,98$ \\
$\mathrm{VAL} / \mathrm{SAU}$ & $\mathrm{R} \$ 2.668,98$ \\
$\mathrm{RA} / \mathrm{SAU}$ & $\mathrm{R} \$ 2.398,32$ \\
$\mathrm{CI} / \mathrm{PB}$ & $50,02 \%$ \\
$\mathrm{DEP} / \mathrm{PB}$ & $7,83 \%$ \\
$\mathrm{RA} / \mathrm{PB}$ & $37,87 \%$ \\
$\mathrm{RA} / \mathrm{UTH}$ & $\mathrm{R} \$ 19.186,52$ \\
$\mathrm{RA} / \mathrm{UTH} / \mathrm{MÊS}$ & $\mathrm{R} \$ 1.598,88$ \\
$\mathrm{RA} / \mathrm{NRS}$ & 1,68 \\
\hline
\end{tabular}

Fonte: Elaborado pelos autores, com base nos dados da pesquisa. 
Figura 5 - Valor Agregado Líquido e Nível de Reprodução Simples da UPA-2.

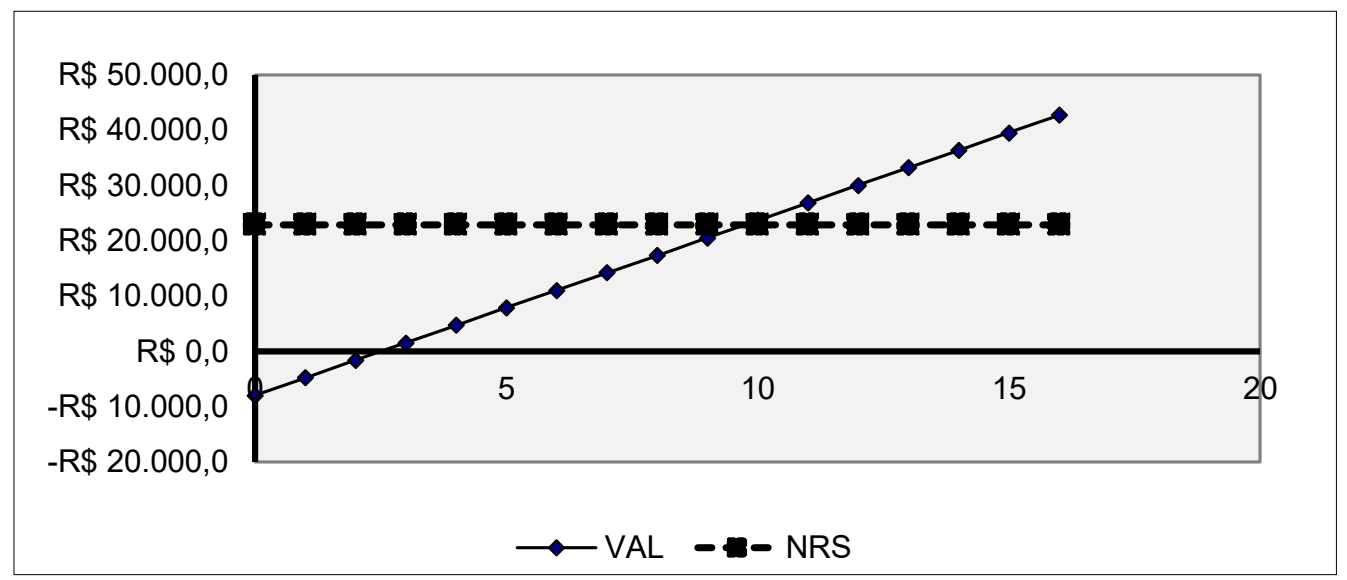

Fonte: Elaborado pelos autores, com base nos dados da pesquisa.

A bovinocultura de corte, além de ser a atividades que tem maior renda agrícola, também proporciona a maior RA por unidades de área e também por unidade de trabalho homem, seguido pela bovinocultura de leite (Figura 6). O milho apresentou maior retorno em renda agrícola por unidade de área em relação à soja. Isto é em grande parte devido à baixa produtividade obtida na cultura da soja (41sc/ha). Caso a produtividade da soja fosse de $50 \mathrm{sc} / \mathrm{ha}$ (produtividade da UPA 1) a RA/ UTH seria maior que a do milho, mas a RA/ha continuaria menor que a do milho, devido à elevada depreciação da atividade. Dessa forma, sugere-se que a cultura da soja seja mantida devido à capacidade instalada, ou seja, maquinas e implementos para a cultura, e também visando rotação de cultura com o milho, mas é preciso aumentar a produtividade, necessitando de assistência técnica para isso.

É aconselhável manter as atividades visando à diversificação e a redução de risco da UPA. Uma alternativa seria aumentar a produtividade em leite. Entretanto, devido à limitação de mão de obra, isso seria capaz se aumentasse a produtividade das vacas. Aumentando em 5 litros/vaca, mediante aumento da alimentação comprada geraria um incremento na RA de 14,7\%. A RA/UTH seria de R $37.017,84$, a RA/ PB seria de 53,90\% e a RA/NRS passaria ser de 3,24. O preço de venda do leite foi de $\mathrm{R} \$ 0,83$ bem abaixo dos R $\$ 0,96$ praticados pela UPA 1 e 3, com isso houve redução significativa da RA, sendo que com um preço de $\mathrm{R} \$ 0,96$ a RA/há seria de $\mathrm{R} \$ 1.889,054$. 
Figura 6 - Desempenho da RA/ha e da RA/UTH na UPA-2.

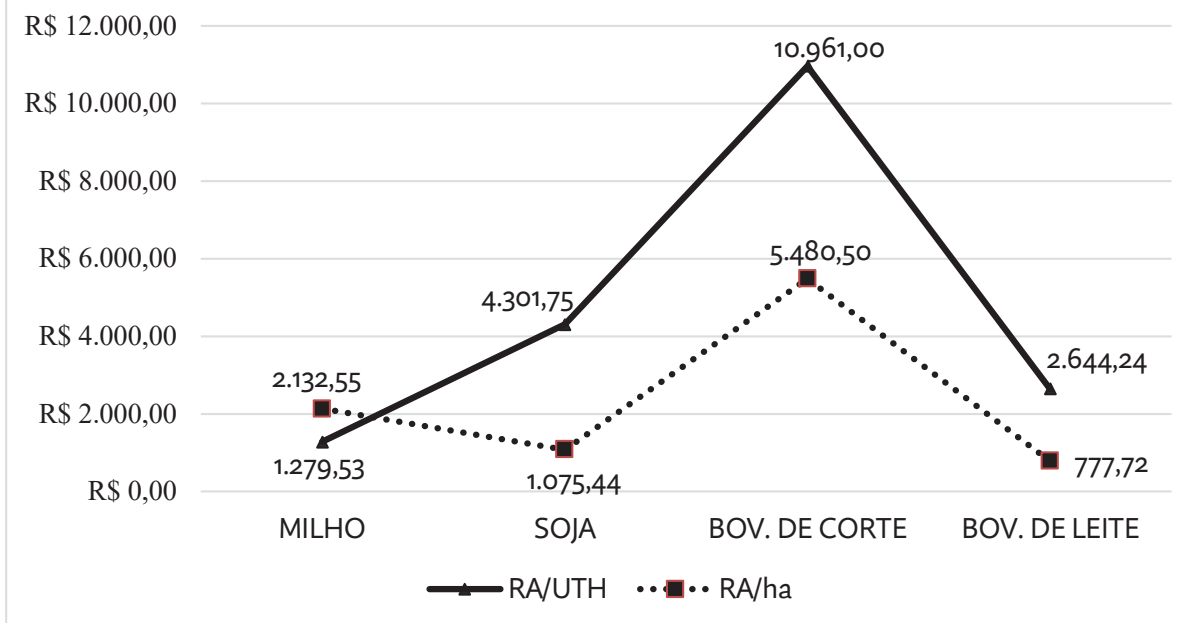

Fonte: Elaborado pelos autores, com base nos dados da pesquisa.

\section{UPA-3: PRODUÇÃO DE GRÃOS (MILHO E SOJA) E BOVINOCULTURA DE LEITE}

A UPA-3 possui uma área de 17 ha, sendo 12 há próprias e 5 ha arrendadas, onde são produzido 6 ha de soja, 6 ha de milho para silagem, 1 ha de milho para grãos para consumo e 2,5 ha para pastagem e 1,5 ha de mato, perfazendo uma Superfície Agrícola Útil (SAU) de 14,5 ha. AUPA tem 25 vacas para produção de leite e conta com 2 UTH.

Tem na bovinocultura de leite sua atividade principal. De acordo com a Tabela 3 aUPA conseguiu auferir no último ciclo produtivo uma RA anual de R $\$ 17.862,83$ por UTH, significando uma RAmensal de $\mathrm{R} \$ 1.488,57$, sendo 1,56 vezes o NRS $(\mathrm{SM}=\mathrm{R} \$ 954,00)$.

Do total da RA da UPA $87,25 \%$ é referente à bovinocultura de leite, $11,10 \%$ relativo à soja e $1,65 \%$ relativo ao milho. $30,64 \%$ do $\mathrm{PB}$ gerado na propriedade são convertidos em RA, sendo que a maior parte do rebate do produto bruto corresponde ao CI, 57,31\% do total. Já a depreciação abate 9,11\% do PB.

Dessa forma, a UPA gera um PB/SAU de R\$ 8.040,58, restando ao final uma RA/SAU R $\$ 2.463,84$.

O desempenho das atividades como demonstrado na Figura 7 evidencia a importância da bovinocultura de leite como fonte de renda, visto que esta foi capaz de prover com um RA/UTH de R\$ 15.608,65, bem acima da soja. Esse valor já é capaz de fornecer uma renda mensal por UTH de R $\$ 1.488,57$, correspondendo a 1,56 vezes superiores ao NRS ( $\mathrm{SM}=\mathrm{R} \$ 954,00)$.

O NRS é atingido com 9,76 ha (Figura 8). Contudo, pela segurança e importância na diversificação da propriedade não se recomenda a eliminação do milho usado no consumo intermediário e da soja, uma vez que a análise realizada leva em conta 
somente um ciclo produtivo, impossibilitando analises mais amplas. Mantida a cultura da soja deve-se aumentar a produtividade atual de $33 \mathrm{sc} /$ ha através da assistência técnica e extensão rural. Com uma produtividade igual a UPA 1 (50 sc/ha) a RA/ha subiria para $\mathrm{R} \$ 1.075,43$.

Tabela 3 - Indicadores econômicos da UPA com sistema de produção de grãos (milho e soja) e bovinocultura de leite.

\begin{tabular}{l|l}
\hline INDICADORES GERAIS & VALORES \\
\hline PB/SAU & $\mathrm{R} \$ 8.040,58$ \\
$\mathrm{VAB} / \mathrm{SAU}$ & $\mathrm{R} \$ 3.432,58$ \\
$\mathrm{VAL} / \mathrm{SAU}$ & $\mathrm{R} \$ 2.700,08$ \\
$\mathrm{RA} / \mathrm{SAU}$ & $\mathrm{R} \$ 2.463,84$ \\
$\mathrm{CI} / \mathrm{PB}$ & $57,31 \%$ \\
DEP/PB & $9,11 \%$ \\
$\mathrm{RA} / \mathrm{PB}$ & $30,64 \%$ \\
$\mathrm{RA} / \mathrm{UTH}$ & $\mathrm{R} \$ 17.862,83$ \\
$\mathrm{RA} / \mathrm{UTH} / \mathrm{MÊS}$ & $\mathrm{R} \$ 1.488,57$ \\
$\mathrm{RA} / \mathrm{NRS}$ & 1,56 \\
\hline
\end{tabular}

Fonte: Elaborado pelos autores, com base nos dados da pesquisa.

Figura 7 - Desempenho da RA/ha e da RA/UTH na UPA-3.

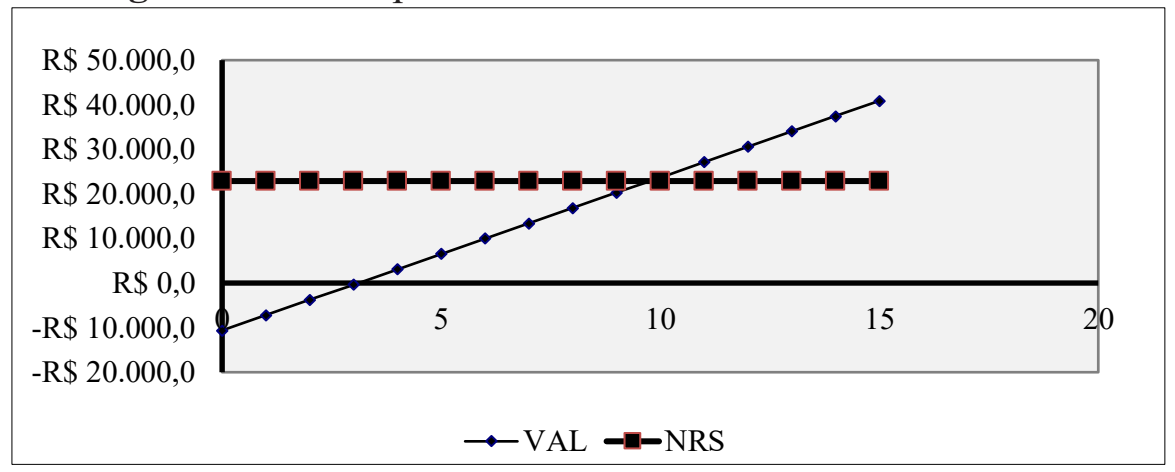

Fonte: Elaborado pelos autores, com base nos dados da pesquisa. 
Figura 8 - Valor Agregado Líquido e Nível de Reprodução Simples da UPA-3.

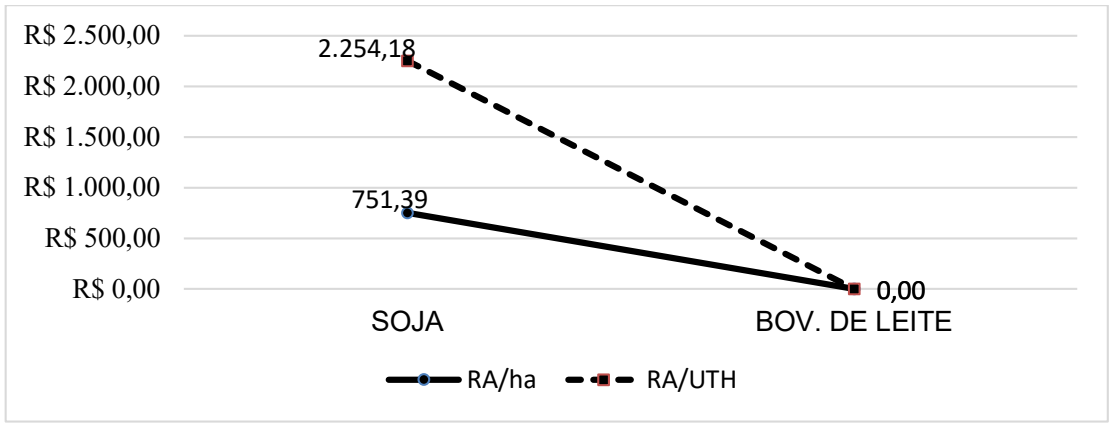

Fonte: Elaborado pelos autores, com base nos dados da pesquisa.

\section{CONCLUSÕes}

A evolução histórica, baseada nos relatos dos participantes da pesquisa, confirma os estudos de autores sobre ciclos de ocupação e produção na região e permite um olhar mais qualificado do contexto atual.

Os principais períodos históricos de exploração primária e/ou econômica, informados nas entrevistas, principiam com o momento de ocupação do território como local de sobrevivência após o evento revolucionário de 1923, onde maragatos em fuga ocuparam lugares ermos, cultivaram pequenas "quartas", criaram suínos soltos e completavam a alimentação pelo extrativismo.

Posteriormente, até o final da década de 1930, o extrativismo madeireiro destinado à exportação através das "balsas" do Rio Uruguai, principalmente de Cedro (Cedrela fissilis) e Grápia (Apuleia leiocarpa), formou o principal quadro econômico.

O terceiro período é a ocupação do território por colonizadores, que reproduziu em certa medida os sistemas anteriores, mas nesse, as lavouras de subsistência foram progressivamente ocupando áreas de floresta, cuja madeira era utilizada localmente para construções de moradias e de infraestruturas das propriedades ou urbanizações próximas. Já no começo da década de 1950, após as derrubadas da vegetação originária, foram alargando a produção de feijão, mandioca, milho e trigo para subsistência e comercialização de excedentes, intensificando também a criação de animais, com mesmos objetivos, especialmente a suinocultura (com apogeu na década de 1960), atribuindo valor extra ao milho disponível.

Adveio então, gradativamente, o período de monocultura: primeiro do trigo e posteriormente trigo-soja com expansão de lavouras mecanizadas. A substituição do trigo por áreas de aveia e azevém destinados a cobertura vegetal e/ou pastoreio 
de inverno com intensificação de produção de grãos no verão repartindo áreas soja e milho, caracterizou o fim da década de 1980 até meados de 2000. Hoje há a intensificação de áreas de cobertura vegetal, com aveia no inverno, cultivo de milho e em sucessão soja na mesma área.

A agricultura, que no início foi eventual, foi se intensificando na utilização de recursos disponíveis. Antes, era a utilização, pousio e novo cultivo. Agora, pelos relatos e observação direta, pelo menos três cultivos em sequência (aveia, milho, soja) na mesma área. Com a intensificação, aumentou a retirada de grãos e nutrientes dessas áreas e a importação de insumos externos, transformam a agricultura no limítrofe do parque em uma atividade altamente demandadora de recursos, financeiros, energéticos e químicos. Os principais produtos utilizados são fertilizantes e agrotóxicos (herbicidas de dessecação total, inseticidas e fungicidas). A área protegida sofre em sua bordadura, impacto principalmente da deriva de pulverizações desses produtos.

$\mathrm{Na}$ análise econômica, as três UPAs estudadas são economicamente viáveis, com retorno maior que o custo de oportunidade (salário mínimo nacional), uma vez que todas apresentaram RA/NRS superior a 1. No entanto, é possível buscar melhorias de renda com manutenção da diversificação da produção e mudanças suaves e continuas nas atividades, com especial atenção para a bovinocultura de leite e a soja.

A tabela 4 apresenta alguns indicadores importantes para possíveis interferências nessas atividades. Com relação à bovinocultura de leite a UPA 1 conseguiu os melhores resultados financeiros, enquanto a UPA 2 teve os piores resultados, em parte explicado pela baixa produtividade (Litro/vaca), baixo preço de venda e elevada lotação de animais (Vacas/ha), em relação a UPA 1. A UPA 3 obteve vários indicadores intermediários, porém com a mais elevada lotação de animais (Vacas/ ha), podendo ser um ponto a ser alterado.

Mantendo a capacidade instalada e os mesmos níveis de produção é possível determinar o preço de equilíbrio (RA nula) para a atividade. Dessa forma, para a UPA 1 o preço de equilíbrio é $\mathrm{R} \$ 0,51$, ou seja, abaixo desse valor a receita com a venda do produto não cobre a totalidade do CI, DEP e DVA, resultando em RA negativa. Para a UPA 2 e 3 o preço de equilíbrio é R\$ 0,75 e R\$ 0,67, respectivamente.

A atividade soja apresentou produtividades discrepantes entre as UPAs, sendo a principal causa de baixa RA/ha da UPA 3, comparando com as UPAs 1 e 2 (Tabela 4). Buscando uma RA positiva, área mínima para o cultivo da soja é de 1,9 ha para a UPA-1, de 2,3 ha para a UPA-2 e 3,2 ha para a UPA-3. Os preços de equilíbrio da soja são $R \$ 25,20, R \$ 31,39$ e $R \$ 39,03$, respectivamente, conforme apresentados na tabela. 
Tabela 4 - Síntese dos indicadores econômicos para as UPAs estudadas.

\begin{tabular}{|c|c|c|c|c|}
\hline & & UPA 1 & UPA 2 & UPA 3 \\
\hline & $\mathrm{N}^{\circ}$ de vacas & 17 & 17 & 25 \\
\hline \multirow{7}{*}{ Leite } & Vacas/ha & 1,79 & 2,50 & 2,94 \\
\hline & Litro/vaca & 23,52 & 11,66 & 14,4 \\
\hline & CI/vacas & $\mathrm{R} \$ 4.523,06$ & $\mathrm{R} \$ 2.981,71$ & $\mathrm{R} \$ 2.672,64$ \\
\hline & Preço de venda & $\mathrm{R} \$ 0,96$ & $\mathrm{R} \$ 0,83$ & $\mathrm{R} \$ 0,96$ \\
\hline & $\mathbf{R A} / \mathbf{h a}$ & $\mathrm{R} \$ 5.591,10$ & $\mathrm{R} \$ 777,72$ & $\mathrm{R} \$ 3.672,62$ \\
\hline & RA/vaca & $\mathrm{R} \$ 3.124,44$ & $\mathrm{R} \$ 311,09$ & $\mathrm{R} \$ 1.248,69$ \\
\hline & Preço de equilíbrio & $\mathrm{R} \$ 0,51$ & $\mathrm{R} \$ 0,75$ & $R \$ 0,67$ \\
\hline \multirow{5}{*}{ Soja } & (sc/ha) & 50 & 41 & 33 \\
\hline & Preço de venda & $\mathrm{R} \$ 60,00$ & $\mathrm{R} \$ 57,00$ & $\mathrm{R} \$ 61,80$ \\
\hline & $\mathbf{R A} / \mathbf{h a}$ & $\mathrm{R} \$ 1.878,24$ & $\mathrm{R} \$ 1.075,44$ & $\mathrm{R} \$ 751,39$ \\
\hline & Área mínima & 1,9ha & 2,3ha & $3,2 \mathrm{ha}$ \\
\hline & Preço de equilíbrio & $R \$ 25,20$ & $R \$ 31,39$ & $R \$ 39,03$ \\
\hline
\end{tabular}

Fonte: Elaborado pelos autores, com base nos dados da pesquisa.

\section{OUTRAS RECOMENDAÇÕES DO ESTUDO}

Os relatos dos participantes da pesquisa lindeiros e guarda-parque coadunam com as informações registradas no "Plano de manejo do Parque Estadual do Turvo" (p.192, 2005) que relata a presença de "revolucionários" maragatos na região em busca de refúgio. Resquícios internos ao parque (a morada dos pais de Sarampião, junto ao Arroio Mairosa) e o Cemitério denominado "do Barulho" (o nome é fruto da alcunha "barulho" de antigo morador das proximidades e não de sons provenientes dele como poderia se intuir), são exemplos satisfatórios para indicar a necessidade de um resgate histórico da região, que possibilitaria conciliar a história e atividades de turismo já existentes, do parque e de circuito municipal. Podem-se inferir alguns problemas da caça e pesca ilegal, com base no fato de que um guarda do parque expressa que "diminuiu bastante, mas é difícil combater cem por cento, pois parece doença tipo de jogador, são viciados". Houve tempos mais complicados e nos dias atuais há uma conscientização da proibição e que os lindeiros ajudam a cuidar e denunciar quando observam a atividade. A relação com moradores lindeiros pode ser potencializada na defesa do PET, a partir da interação, diálogo frequente e troca de informações entre autoridades e moradores, que em sua maioria mostram-se comprometidos com a ideia de conservação. 
Outro problema para o qual é necessário ter mais atenção são os danos por uso de agrotóxicos perto dos limites do parque e, principalmente, próximos a cursos d'água que ingressam na floresta. Assim, seria recomendável a não utilização destes produtos e/ou o emprego de zonas de amortização, como cortinas vegetais, a exemplo do entorno da área urbana do município.

\section{REFERÊNCIAS}

ANA. Governo Federal. Agência Nacional de Águas. Disponível em: http://www2. ana.gov.br/Paginas/portais/bacias/uruguai.aspx > Acesso em Jan/2016.

BRACK, P., BUENO, R. M., FALKENBERG, D. B., PAIVA, M. R. C., SOBRAL, M. \& STEHMANN, J. R. Levantamento florístico do Parque Estadual do Turvo, Tenente Portela, Rio Grande do Sul, Brasil. Roessléria, 7(1): 69-94, 1985.

GARCIA FILHO, D. P. Guia metodológico - diagnóstico de sistemas agrários. Brasília, Incra, FAO, 1999. Disponível em: WWW.incra.gov.br/fao/> Acesso em Jan/2016.

HOFFMANN, R et AL. Administração da empresa agrícola. Pioneira, São Paulo, $5^{\circ}$ edição, 1987.

LIMA, A. J. P. et al. Administração da unidade de produção familiar: modalidade de trabalho com agricultores. Editora UNIJUÍ, Ijuí, RS, $3^{\circ}$ edição, 224 p. 2005.

RIO GRANDE DO SUL. Secretaria Estadual do Meio Ambiente (SEMA - RS). Plano de manejo do Parque Estadual do Turvo - RS. Porto Alegre: Divisão de Unidades de Conservação do Estado do Rio Grande do Sul, 348 p., 2005.

ROSA, P. A., BREUNIG, Fábio Marcelo, BALBINOT, Rafaelo, GALVÃO, Lênio Soares. Dinâmica da Floresta do Parque Estadual do Turvo com Índices de Vegetação. Revista Floresta e Ambiente, 20(4) p. 487-499, 2013

SILVA NETO, B., LIMA, A. P. de, BASSO, D. Teoria dos Sistemas Agrários: uma nova abordagem do desenvolvimento da agricultura. Revista de Extensão Rural, UFSM, Santa Maria, RS, ano IV, p. 6-19, jan-dez/1997. 
SILVA NETO, B., BASSO, D. Sistemas Agrários do Rio Grande do Sul: análise e recomendações de políticas. Editora UNIJUÍ, Ijuí, RS, $2^{\circ}$ edição, 336 p., 2015.

SCHIRMER, L. "Flores da Cunha de corpo inteiro", Ed. RBS Publicações, Porto Alegre, RS, 2007.

WALLAUER, J. P.; ALBUQUERQUE, E. P. Lista preliminar dos mamíferos observados no Parque Florestal do Turvo, Tenente Portela, Rio Grande do Sul, Brasil. Roessiléria, v. 8, n. 2, p. 179-185, 1986. 